Acknowledgements We thank J. Harte and J. Green for comments on the manuscript. U.B. is supported by the German Academy of Naturalists Leopoldina and by funds from the German Federal Ministry of Education and Science. A.O. is supported by the National Center for Environmental Research (NCER) STAR Program, EPA. N.D.M is supported by the Cornell Telluride Association, Cornell Center for Applied Mathematics, and the US National Science Foundation Biocomplexity, Biological Databases and Informatics, Information Technology Research, and Interdisciplinary Graduate Education and Research Training programs.

Competing interests statement The authors declare that they have no competing financial interests.

Correspondence and requests for materials should be addressed to U.B. (brose@sfsu.edu).

\section{Pervasive alteration of tree communities in undisturbed Amazonian forests}

\author{
William F. Laurance ${ }^{1,2}$, Alexandre A. Oliveira ${ }^{4}$, Susan G. Laurance ${ }^{1,2}$, \\ Richard Condit ${ }^{1}$, Henrique E. M. Nascimento ${ }^{1}$, Ana C. Sanchez-Thorin ${ }^{1}$, \\ Thomas E. Lovejoy ${ }^{2}$, Ana Andrade ${ }^{2}$, Sammya D'Angelo ${ }^{2}$, \\ José E. Ribeiro ${ }^{3}$ \& Christopher W. Dick
}

${ }^{1}$ Smithsonian Tropical Research Institute, Apartado 2072, Balboa, Republic of Panamá

${ }^{2}$ Biological Dynamics of Forest Fragments Project, and ${ }^{3}$ Department of Botany, National Institute for Amazonian Research (INPA), CP 478, Manaus, AM 69011-970, Brazil

${ }^{4}$ Department of Biology, University of São Paulo, Avenida Bandeirantes 3900, Ribeirão Preto-São Paulo, SP 14040-901, Brazil

Amazonian rainforests are some of the most species-rich tree communities on earth ${ }^{1}$. Here we show that, over the past two decades, forests in a central Amazonian landscape have experienced highly nonrandom changes in dynamics and composition. Our analyses are based on a network of 18 permanent plots unaffected by any detectable disturbance. Within these plots, rates of tree mortality, recruitment and growth have increased over time. Of 115 relatively abundant tree genera, 27 changed significantly in population density or basal area-a value nearly 14 times greater than that expected by chance. An independent, eight-year study in nearby forests corroborates these shifts in composition. Contrary to recent predictions ${ }^{2-5}$, we observed no increase in pioneer trees. However, genera of faster-growing trees, including many canopy and emergent species, are increasing in dominance or density, whereas genera of slower-growing trees, including many subcanopy species, are declining. Rising atmospheric $\mathrm{CO}_{2}$ concentrations ${ }^{6}$ may explain these changes, although the effects of this and other large-scale environmental alterations remain uncertain. These compositional changes could have important impacts on the carbon storage, dynamics and biota of Amazonian forests.

Recent studies suggest that undisturbed Amazonian forests are becoming more dynamic over time, with higher rates of tree mortality and turnover ${ }^{4,5}$, and that carbon storage ${ }^{7-10}$ and productivity $^{11}$ in these forests are increasing. In addition, lianasclimbing woody vines that often thrive in disturbed forest-appear to be increasing in size and abundance ${ }^{12}$. A plausible cause of these changes is increasing plant fertilization caused by rising atmospheric $\mathrm{CO}_{2}$ concentrations ${ }^{2-13}$, although other large-scale phenomena, such as alterations in regional temperature ${ }^{14}$, rainfall $^{15,16}$, available solar radiation ${ }^{17}$, or nutrient deposition ${ }^{18}$, might also play a role. However, no studies have assessed the effects of such large-scale changes on the taxonomic composition of Amazonian tree communities, which greatly influences the architecture, dynamics and ecological functioning of these forests.

We assessed long-term changes in tree-community composition within a network of 18 discrete, one-hectare plots in central Amazonia (Supplementary Figs 1 and 2). The plots span an area of about $300 \mathrm{~km}^{2}$, are randomly located with respect to local topography, and are positioned at least $300 \mathrm{~m}$ away from any clearings to avoid edge effects ${ }^{19,20}$. Plots exhibited no evidence of current or past disturbance from logging, fires, hunting or major windstorms, although two plots experienced small wet-season floods that caused temporary increases in tree mortality. All plots were established from 1981 to 1987 and re-censused at roughly fiveyear intervals for an average of $15.0 \mathrm{yr}$ (range $=11.4$ to $18.2 \mathrm{yr}$ ), with the final census of each in 1999 or 2000 . Within each plot, all trees ( $\geq 10 \mathrm{~cm}$ diameter at breast height, DBH) were marked with permanent tags, mapped, measured for trunk diameter, and identified on the basis of sterile or fertile material. In total, nearly 13,700 trees were recorded.

We assessed changes in the abundance of tree genera, rather than species, for three reasons. First, $88 \%$ of tree species in our study area are too rare $(<1$ individual per hectare) to allow robust analyses of population trends. Second, congeneric species of Amazonian trees tend to be similar ecologically ${ }^{21,22}$, so analyses at the genus level capture most of the relevant information. Third, $95.3 \%$ of study trees were positively identified to genus, whereas a smaller percentage was identified to species.

We encountered 244 tree genera in our plots, of which 115 were sufficiently abundant (initially present in at least 8 of 18 plots) to permit rigorous analysis. For each genus, we used bootstrapping (see Methods) to test for changes in population density and basal area (a strong correlate of tree biomass) between the first and final

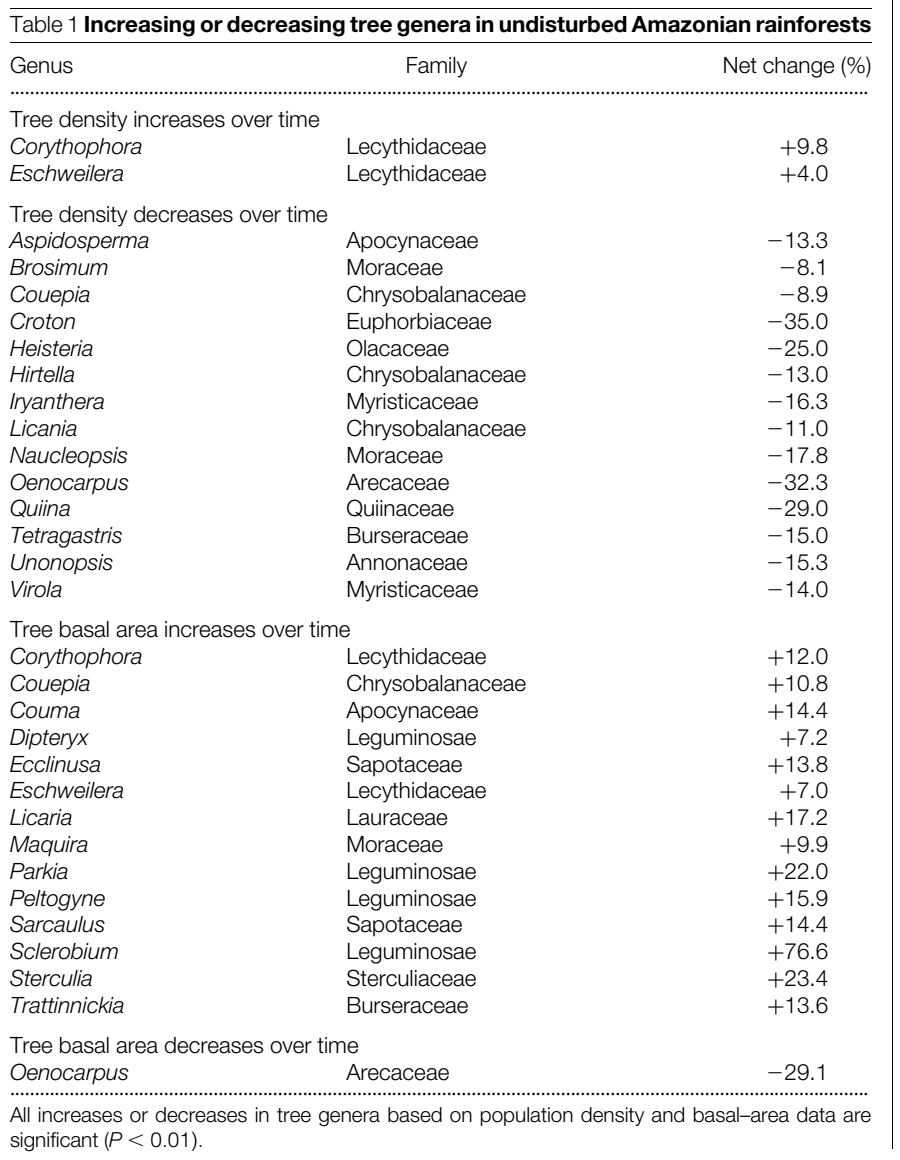


censuses of the plots. Using a conservative 1\% significance level in our tests, we expected-for each parameter-that about one out of 115 genera would show a significant change by chance alone.

Overall, we found 31 significant changes, with 14 genera increasing in basal area and 14 genera declining in density (Table 1). One genus, Couepia, simultaneously increased in basal area while declining in density (the result of increased tree growth but high mortality of small individuals), whereas three other genera either decreased (Oenocarpus) or increased (Corythophora, Eschweilera) in both density and basal area. Thus, excluding Couepia, 13 genera declined in density, and 13 genera increased in basal area, sometimes dramatically (Table 1). Most genera that declined in density did not also decline in basal area because of the accelerated growth of the surviving trees (see below).

Mortality rates differed between the 13 increasing and 13 decreasing genera. Decreasing genera had much higher mortality than increasing genera $\left(1.57 \pm 0.90\right.$ versus $0.51 \pm 0.31 \% \mathrm{yr}^{-1} ; t=4.66$, degrees of freedom, d.f. $=24, P=0.0001$; $t$-test with $\log$ transformed data), whereas recruitment rates did not differ between the two $\left(0.50 \pm 0.48\right.$ versus $0.69 \pm 0.42 \% \mathrm{yr}^{-1} ; t=1.06$, d.f. $=24$, $P=0.30 ; t$-test). Recruitment rates of increasing and decreasing genera were both on average lower than the stand-level rate $\left(1.06 \% \mathrm{yr}^{-1}\right.$ ) because they included few pioneers (which have higher recruitment).

These shifts in tree communities were not driven by large overall
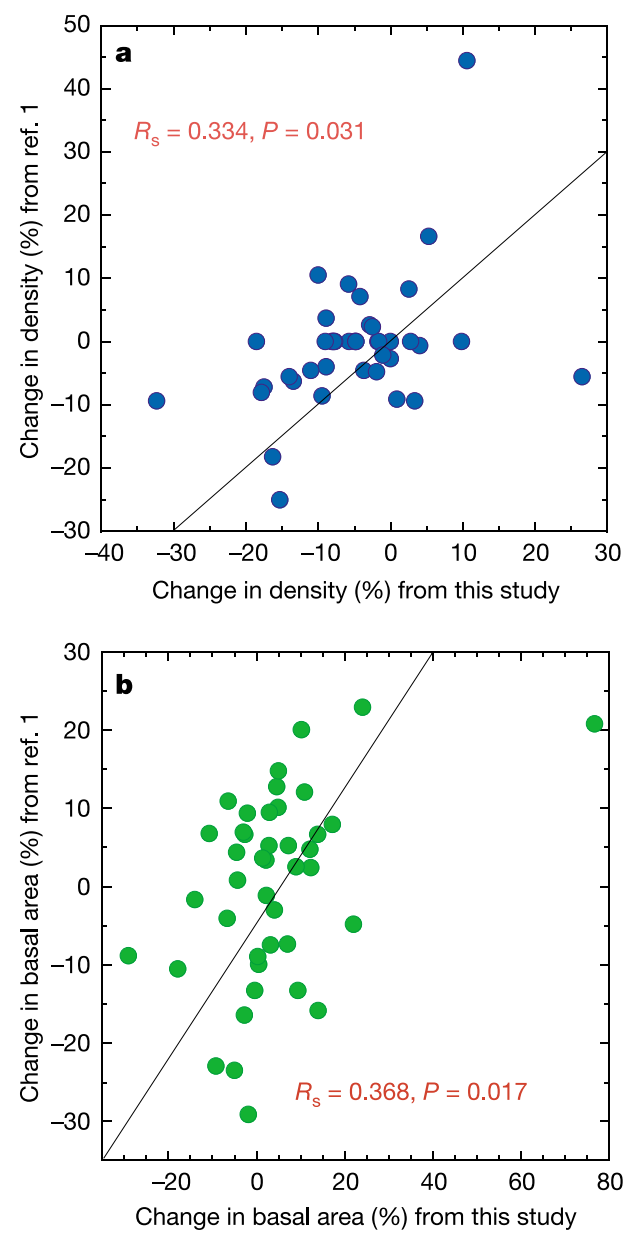

Figure 1 Mean percentage changes in (a) population density and (b) basal area of 42 Amazonian tree genera in two different long-term studies. (Correlation coefficients are for Spearman rank tests.) Data are from the 18 one-hectare plots in this study and the three one-hectare plots of ref. 1 . The diagonal line in each figure shows $y=x$. changes in tree density or basal area. During the course of our study, average tree density declined by $1.1 \%$, whereas average basal area rose by $1.9 \%$. Neither change was statistically significant $(P>0.09$; paired $t$-tests).

Two lines of evidence confirm that these compositional changes reflect underlying biological processes, not sampling errors. First, randomization tests revealed that the observed changes in density $(P=0.001)$ and basal area $(P=0.002)$ for all 115 genera were consistent across the 18 plots (see Methods). Second, we contrasted our results with those of a separate, eight-year study ${ }^{1}$, in which trees in three one-hectare plots were censused in undisturbed forest about $6 \mathrm{~km}$ east of our study area (see Methods). Changes over time in both density and basal area of genera were significantly and positively correlated between the two studies (Fig. 1). Thus, parallel studies by two separate teams of investigators revealed similar patterns of change.

Do the increasing and declining tree genera differ biologically? We reviewed available literature and Internet resources and used data from our long-term study to quantify key ecological traits for most genera (Supplementary Table 1). The 13 increasing genera and 13 decreasing genera differed in growth form: all of the former were canopy or emergent trees, whereas six $(46 \%)$ of the latter were subcanopy trees (the remainder being canopy or emergent trees), a highly significant difference $(G=10.15$, d.f. $=1, P=0.001$; $G$-test). Similarly, among all 115 genera, there was a clear tendency for large trees to increase in population density (Fig. 2) and basal area at the expense of small trees.

Surprisingly, successional status differed little between the 13 increasing and 13 declining genera; old-growth trees dominated (77\%) both groups. In addition, none of the major pioneer genera (Annona, Cecropia, Croton, Goupia, Jacaranda, Miconia, Pourouma, Vismia) increased significantly in density or basal area, either individually or when pooled (Supplementary Table 2). Nevertheless, both median $(t=2.28$, d.f. $=24, P=0.032)$ and maximum ( $t=2.07$, d.f $=24, P=0.049)$ absolute growth rates were significantly higher in the increasing than declining genera ( $t$-tests with log-transformed data). Similar patterns were evident when all genera that increased and declined in density (not just those that changed significantly) were compared. Collectively, these trends suggest that genera with higher absolute growth rates, including many canopy and emergent trees but not pioneers, are increasing at the expense of slower-growing genera, which include many smaller, old-growth subcanopy trees.

The tree community is also changing in taxonomic composition. The increasing genera are dominated $(57 \%)$ by three families (Leguminosae, Lecythidaceae, Sapotaceae) that are not represented

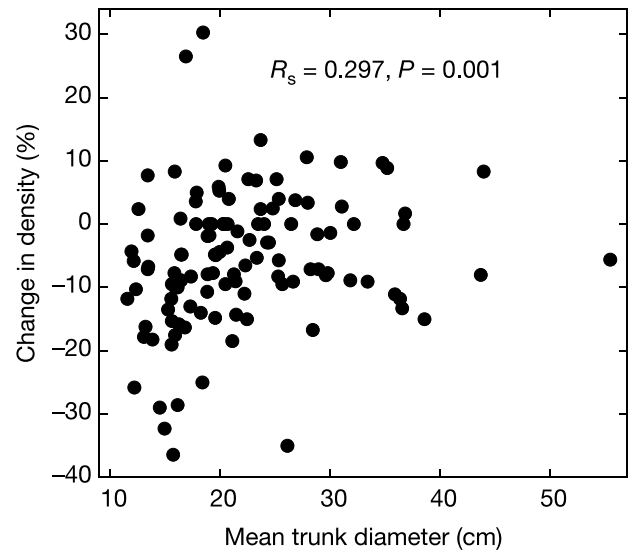

Figure 2 Relationship between tree size and long-term population change for Amazonian tree genera. (The correlation coefficient is for a Spearman rank test.) 
among declining genera, whereas most (64\%) declining genera are in families (Arecaceae, Annonaceae, Chrysobalanaceae, Moraceae, Myristicaceae) that are poorly represented among increasing genera (Table 1).

To help identify the underlying causes of these alterations, we assessed dynamical changes in the tree communities. We divided census data for each plot into two roughly equal intervals (1984-91 and 1992-99) and then contrasted overall rates of tree mortality and recruitment between the two intervals. Both rates rose markedly from interval 1 to interval 2 (Fig. 3); thus our forests clearly became more dynamic over time. Mortality and recruitment rates did not rise significantly for the increasing and declining genera, although the latter consistently had higher mortality than recruitment (Fig. 3).

Moreover, for $87 \%$ of genera, rates of trunk growth accelerated between intervals 1 and 2 (Fig. 4). This is the first demonstration of enhanced growth across a wide range of tropical tree genera, and is consistent with stand-level increases in tree growth across South American forests ${ }^{11}$. Notably, the average increase in absolute growth rate was higher among increasing genera than declining genera $\left(0.55 \pm 0.49\right.$ versus $\left.0.19 \pm 0.17 \mathrm{~mm} \mathrm{yr}^{-1}\right)$; the average for genera showing no significant change was intermediate $\left(0.41 \pm 0.50 \mathrm{~mm} \mathrm{yr}^{-1}\right)$. This difference did not occur solely because increasing genera were often large in size and decreasing genera often small: in relative terms, growth accelerated much more in increasing $(57 \%)$ than decreasing $(22 \%)$ genera.

a

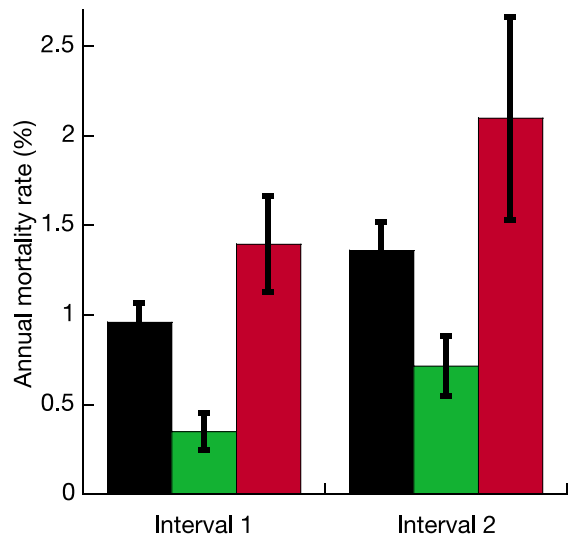

b

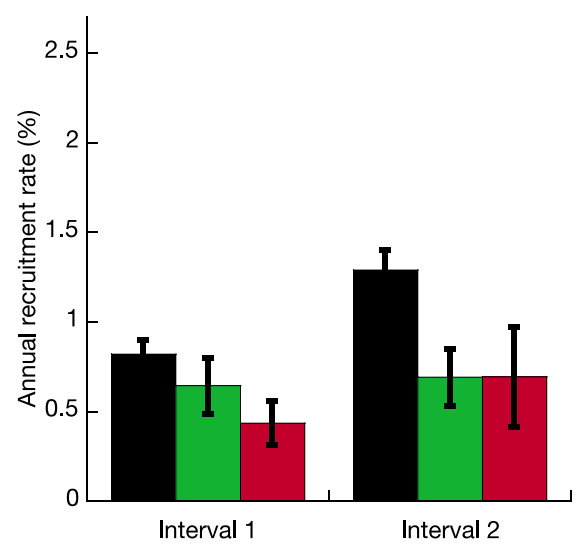

Figure 3 Mortality (a) and recruitment (b) rates ( \pm 1 s.e.m.) for increasing and decreasing genera. Data are shown for all trees (black bars), for 13 genera that increased in basal area (green bars), and for 13 genera that declined in density (red bars). Overall mortality $(t=-2.38$, d.f. $=17, P=0.03)$ and recruitment $(t=-4.45$, d.f. $=17$, $P=0.0003$ ) accelerated from interval 1 (around 1984-91) to interval 2 (around 1992-99). However, there was no significant change over time $(P>0.11)$ in mortality or recruitment for the increasing and decreasing genera (paired $t$-tests).
At least four different phenomena might account for these forestwide changes in composition and dynamics. First, the forests of our study area might be in a state of disequilibrium because of ongoing recovery from past disturbance, leading to shifts over time in tree composition. However, the only natural disturbance likely to operate over such large $\left(300 \mathrm{~km}^{2}\right)$ spatial scales would be a major forest fire, and charcoal and phytolith data suggest that our study area has been continuously forested for at least $4,500 \mathrm{yr}^{23}$. Other forms of disturbance, such as windbursts from convectional thunderstorms and wet-season flooding, are patchy and localized, and thus are unlikely to account for the pervasive changes we detected.

Second, the observed changes might reflect differential vulnerability of trees to El Niño-related droughts ${ }^{15,16}$, which increased in frequency during the last century ${ }^{24}$, possibly because of global warming $^{25}$. We found little direct support for this proposition in two separate analyses (Supplementary Tables 3 and 4). The drought hypothesis, however, requires further examination, because strong droughts have apparently caused shifts in tree-community composition in Panama ${ }^{15}$.

Third, the forests might be responding to multi-decadal changes in rainfall that affect forest productivity and species composition. Drier conditions in rainforests may increase tree growth and reproduction $^{26,27}$, possibly because cloud cover is reduced, increasing available sunlight for light-limited trees. Nonetheless, no significant trends in central-Amazon rainfall were evident during our study (Supplementary Table 5) or in the preceding decades ${ }^{28}$, providing little support for this hypothesis.

Finally, changes in floristic composition could be driven by accelerated forest productivity. We believe the most likely cause of higher productivity is rising atmospheric $\mathrm{CO}_{2}$ levels ${ }^{2-13}$, although other agents (such as possible increases in solar radiation from reduced tropical cloudiness ${ }^{17,29}$, and higher airborne nutrient deposition $^{18}$ from increasing forest fires) are also plausible. Of all the hypothesized factors, accelerated productivity best explains key observations of this study: (1) that tree growth, mortality and recruitment have increased markedly, all of which can result from higher productivity ${ }^{2-13}$; (2) that many faster-growing genera are increasing in basal area, possibly because fast-growing trees show stronger growth enhancement under increased $\mathrm{CO}_{2}$ (refs 2, 3, 13); and (3) that forests are experiencing nonrandom changes in

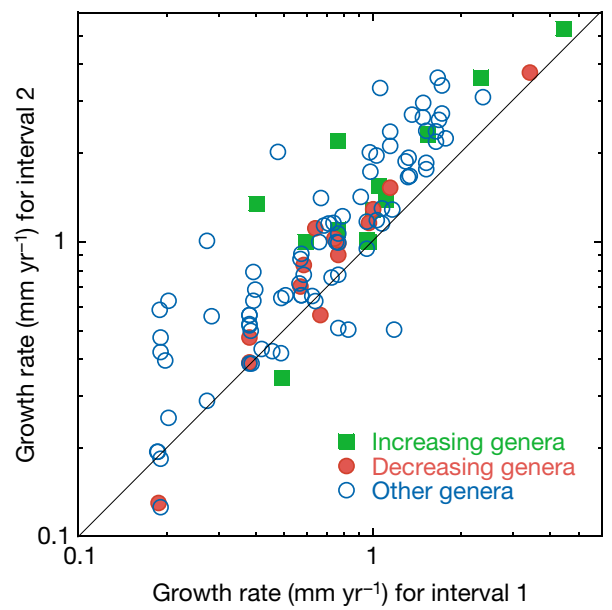

Figure 4 Comparison of median growth rates of Amazonian tree genera between interval 1 (around 1984-91) and interval 2 (around 1992-99). The diagonal line shows $y=x$. Growth rates accelerated markedly over time for all genera $(t=-9.74$, d.f. $=114, P<0.00001$; paired $t$-test), and accelerated significantly more for increasing than for decreasing genera $(t=2.45$, d.f. $=24, P=0.022$; $t$-test for unequal variances). 
species composition, with fast-growing canopy and emergent genera evidently gaining a competitive advantage over smaller, slower-growing genera. That rapidly growing pioneers have not increased in abundance is surprising, but these species usually establish themselves in large treefall gaps $^{2,3,13}$, which may be uncommon in our study area because mortality is greatest among small trees. The group most likely to decline further, we suggest, is old-growth subcanopy species, a highly diverse assemblage that are notable for their slow growth, dense wood and ability to reproduce in full shade ${ }^{30}$.

These changes could have both local and global consequences. Undisturbed Amazonian forests appear to be functioning as an important carbon $\operatorname{sink}^{7-11}$, helping to slow global warming, but pervasive changes in tree communities could modify this effect. In particular, increases in forest carbon storage may be slowed by the tendency of canopy and emergent trees to produce wood of reduced density as their size and growth rate increases ${ }^{30}$, and by the decline of densely wooded subcanopy species. Forest-wide alterations of tree communities, which sustain assemblages of often-specialized pollinators, herbivores, symbiotic fungi and other species, could also have serious ecological repercussions for the diverse Amazonian biota. Further studies are urgently needed to determine whether comparably large shifts in tree communities are occurring throughout the tropics, and to identify the environmental agents driving these changes.

\section{Methods}

\section{Changes in tree density and basal area}

Our null hypothesis was that each tree genus exhibited no significant change in population density or basal area, which is appropriate because total density and total basal area of trees did not change significantly during our study. For each genus, change in mean population density $(\lambda)$ was defined as $\frac{N_{\mathrm{T}}}{N_{\mathrm{T}}}$, where $N_{\mathrm{T}}$ is the final population density and $N_{0}$ is the initial density ( $N$ for each genus was found by averaging population density across all 18 plots). To estimate confidence limits for $\lambda$, we bootstrapped across plots. Eighteen plots were drawn at random, with replacement, and $\lambda$ calculated each time (the same set of plots was used to find $N_{\mathrm{T}}$ and $N_{0}$ ). From 1,000 replicates, the 5th and 995th ranking values of $\lambda$ were taken as the $99 \%$ confidence limits. Observed values of $\lambda$ that fell outside this range were considered significant at the $P \leq 0.01$ level (using a two-tailed test). Because this method is unreliable for genera occurring in a small number of plots, we restricted analyses to genera present in eight or more plots during our initial census (at this frequency, all genera exhibited reasonably stable estimates for recruitment, mortality and growth). We used the same method to test for changes in basal area of each species.

\section{Correlated changes among plots}

We used randomization tests to determine whether the observed changes in density and basal area for all 115 tree genera were more similar among our 18 plots than was expected by chance. To do this we selected nine plots at random and determined the mean per cent change in density for each genus in the plots, and then compared these values to the mean per cent change for each genus in the other nine plots, using Pearson correlations. We repeated this 1,000 times, using random combinations of plots each time. The mean and standard error of the mean (s.e.m.) for the 1,000 correlations were determined, which were then used to calculate a $Z$ statistic $\left(Z=\right.$ mean $\times$ s.e.m. $\left.{ }^{-1}\right)$. We used a one-tailed $Z$-test to determine whether the mean value of the observed correlations was significantly greater than zero. The same procedure was used to test for changes in basal area.

\section{Independent study}

The independent study ${ }^{1}$ used methods that were nearly identical to ours. Three one-hectare plots were censused in August 1991 and again in September 1999. A total of 2,085 trees were recorded in the plots, of which $97.1 \%$ were identified to genus. To minimize effects of smal sample sizes, we included in the analysis the 42 genera with at least ten individuals in the three plots (Fig. 1). All of these genera were present in at least half of our 18 plots.

\section{Ecological traits of tree genera}

For most of the 115 genera in this study, data on growth form and successional status were gleaned from a variety of published and online data sources as well as personal knowledge of the authors (Supplementary Tables 1 and 2). Data on other ecological traits (for example, seed-dispersal syndrome, fruit type) were not available for our genera on a consistent basis. Estimates for median and maximum growth rates, mortality and recruitment rates, and mean trunk diameter were derived from demographic data from our long-term study (Supplementary Table 1). Distributional data on locally occurring species within each significantly changing genus, with respect to major rainfall zones in Amazonia, were mostly derived from online sources (Supplementary Table 3). Finally, an index of drought tolerance for 30 abundant tree species was derived from published and unpublished data from our 18 plots and from other nearby plots in the same study area (Supplementary Table 4).

\section{Changes in forest dynamics and growth}

Stand-level rates of annual mortality and recruitment, and the annual rate of trunk growth for individual tree genera were generated for two largely non-overlapping intervals (approximately 1984 to 1991 and 1992 to 1999). For our 18 plots, the first interval averaged $7.6 \pm 2.5 \mathrm{yr}$ in duration, whereas the second interval averaged $7.4 \pm 0.9 \mathrm{yr}$ in duration; the first interval was more variable in length because the plots were initially established over a six-year period, from 1981 to 1987. Annualized mortality and recruitment data for each plot and interval were estimated using logarithmic models.

To calculate annual growth rates for each genus, the mean annual growth of each tree was determined by subtracting its initial DBH from its final DBH, and dividing by the number of years. The median growth rate was then determined for all trees within the genus. Maximum growth rate was also calculated for each genus, and to reduce the effects of outliers the upper decile of the rates was used as an estimate of maximum growth rate. Growth rates were calculated only for genera that had at least ten live stems in each of the first and second intervals.

Received 22 September 2003; accepted 2 February 2004; doi:10.1038/nature02383.

1. de Oliveira, A. A. \& Mori, S. A. A central Amazonian terra firma forest. I. High tree species richness on poor soils. Biodivers. Conserv. 8, 1219-1244 (1999).

2. Reekie, E. G. \& Bazzaz, F. A. Competition and patterns of resource use among seedlings of five tropical trees grown at ambient and elevated $\mathrm{CO}_{2}$. Oecologia 79, 212-222 (1989).

3. Winter, K. \& Lovelock, C. E. Growth responses of seedlings of early and late successional tropical forest trees to elevated atmospheric $\mathrm{CO}_{2}$. Flora 194, 221-227 (1999).

4. Phillips, O. L. \& Gentry, A. H. Increasing turnover through time in tropical forests. Science 261, 954-958 (1994).

5. Phillips, O. L. et al. Pattern and process in Amazon tree turnover, 1976-2001. Phil. Trans. R. Soc. B. (in the press).

6. Houghton, J. T. et al. (eds) Climate Change 2001: The Scientific Basis (Cambridge Univ. Press, Cambridge, UK, 2001)

7. Grace, J. et al. Carbon dioxide uptake by an undisturbed tropical rain forest in southwest Amazonia, 1992 to 1993 . Science $270,778-780$ (1994).

8. Phillips, O. L. et al. Changes in the carbon balance of tropical forest: Evidence from long-term plots. Science 282, 439-442 (1998).

9. Baker, T. R. et al. Increasing biomass in Amazonian forest plots. Phil. Trans. R. Soc. B. (in the press).

10. Malhi, Y. et al. Carbon dioxide transfer over a central Amazonian rain forest. J. Geophys. Res. 103, 31593-31612 (1998).

11. Lewis, S. L. et al. Concerted changes in tropical forest structure and dynamics: Evidence from 50 South American long-term plots. Phil. Trans. R. Soc. B (in the press).

12. Phillips, O. L. et al. Increasing dominance of large lianas in Amazonian forests. Nature 418, 770-774 (2002).

13. Körner, C. Tropical forests in a $\mathrm{CO}_{2}$-rich world. Clim. Change 39, 297-315 (1998).

14. Clark, D. A., Piper, S. C., Keeling, C. D. \& Clark, D. H. Tropical rain forest tree growth and atmospheric carbon dynamics linked to interannual temperature variation during 1984-2000. Proc. Natl Acad. Sci. USA 100, 5852-5857 (2003).

15. Condit, R., Hubbell, S. P. \& Foster, R. B. Assessing the response of plant functional types to climatic change in tropical forests. J. Veg. Sci. 7, 405-416 (1996).

16. Tian, H. et al. Effect of interannual climate variability on carbon storage in Amazonian ecosystems. Nature 396, 664-667 (1998).

17. Wielicki, B. A. et al. Evidence for large decadal variability in tropical mean radiative energy budget. Science 295, 841-844 (2002).

18. Artaxo, P. et al. Dry and wet deposition in Amazonia: from natural biogenic aerosols to biomass burning impacts. Int. Glob. Atmos. Chem. Newsl. 27, 12-16 (2003).

19. Laurance, W. F. et al. Biomass collapse in Amazonian forest fragments. Science 278, 1117-1118 (1997)

20. Laurance, W. F. et al. Rainforest fragmentation kills big trees. Nature 404, 836 (2000).

21. ter Steege, H. \& Hammond, D. S. Character convergence, diversity, and disturbance in tropical rain forest in Guyana. Ecology 82, 3197-3212 (2001).

22. Casper, B. B., Heard, S. B. \& Apanius, V. Ecological correlates of single-seededness in a woody tropical flora. Oecologia 90, 212-217 (1992).

23. Piperno, D. R. \& Becker, P. Vegetation history of a site in the central Amazon Basin derived from phytolith and charcoal records from natural soils. Quat. Res. 45, 202-209 (1996).

24. Dunbar, R. B. El Niño-clues from corals. Nature 407, 956-959 (2000).

25. Timmermann, A. et al. Increased El Niño frequency in a climate model forced by future greenhouse warming. Nature 398, 694-697 (1999).

26. Wright, S. J. et al. The El Niño Southern Oscillation, variable fruit production, and famine in a tropical forest. Ecology 80, 1632-1642 (1999).

27. Clark, D. A. \& Clark, D. B. Climate-induced annual variation in canopy tree growth in a Costa Rican tropical rain forest. J. Ecol. 82, 865-872 (1994).

28. Malhi, Y. \& Wright, J. Spatial patterns and recent trends in the climate of tropical forest regions. Phil. Trans. R. Soc. Lond. B. (in the press).

29. Lewis, S. L., Malhi, Y. \& Phillips, O. L. Fingerprinting the impacts of global change on tropical forests. Phil. Trans. R. Soc. Lond. B. (in the press).

30. Thomas, S. C. Asymptotic height as a predictor of growth and allometric characteristics in Malaysian rain forest trees. Am. J. Bot. 83, 556-566 (1996).

Supplementary Information accompanies the paper on www.nature.com/nature 
Acknowledgements We thank the many taxonomic specialists and field technicians who collected and identified plant material during the study, and the A. W. Mellon Foundation, the NASA-LBA Program, the Conservation, Food and Health Foundation, the US National Science Foundation, the MacArthur Foundation, the National Institute for Amazonian Research (INPA), and the Smithsonian Institution for support. Comments from O. L. Phillips, J. A. Pounds, S. L. Lewis, S. J. Wright, K. Winter, T. R. Baker, R. K. Didham, R. Harrison, T. A. Kursar and P. D. Coley improved the manuscript

Competing interests statement The authors declare that they have no competing financial interests.

Correspondence and requests for materials should be addressed to W.F.L. (laurancew@tivoli.si.edu).

\section{Sustainable trophy hunting of African lions}

\section{Karyl Whitman, Anthony M. Starfield, Henley S. Quadling \& Craig Packer}

Department of Ecology, Evolution and Behavior, University of Minnesota, 1987 Upper Buford Circle, Saint Paul, Minnesota 55108, USA

In most species, sport hunting of male trophy animals can only reduce overall population size when the rate of removal of males is so high that females can no longer be impregnated ${ }^{1}$. However, where males provide extensive paternal care, the removal of even a few individuals could harm the population as a whole ${ }^{2,3}$. In species such as lions, excessive trophy hunting could theoretically cause male replacements (and associated infanticide ${ }^{4,5}$ ) to become sufficiently common to prevent cubs reaching adulthood. Here we simulate the population consequences of lion trophy hunting using a spatially explicit, individual-based, stochastic model parameterized with 40 years of demographic data from northern Tanzania. Although our simulations confirm that infanticide increases the risk of population extinction, trophy hunting could be sustained simply by hunting males above a minimum age threshold, and this strategy maximizes both the

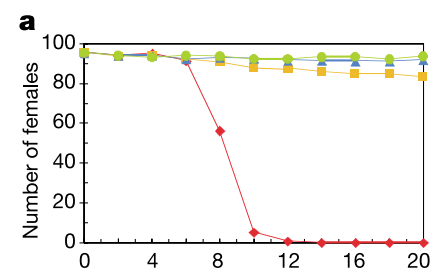

b
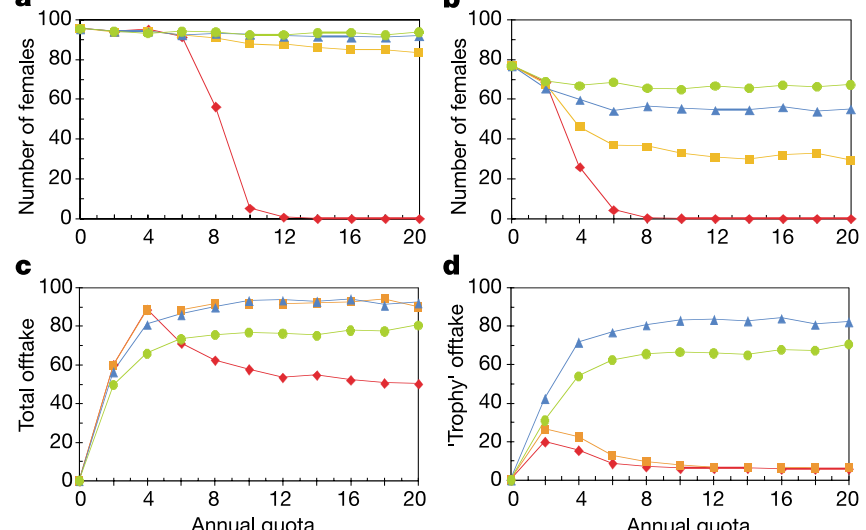

d

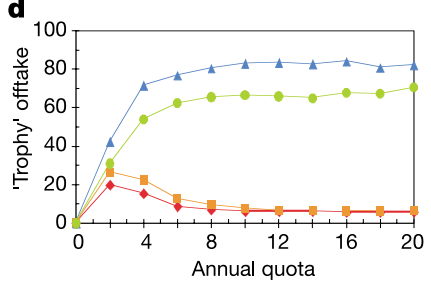

Figure 1 Effects of trophy hunting as a function of quota size and male age. Average outcome after 100 runs is shown from shooting males of the following ages: $\geq 3 \mathrm{yr}$ old (red), $\geq 4 \mathrm{yr}$ (orange), $\geq 5 \mathrm{yr}$ (blue), $\geq 6 \mathrm{yr}$ (green). a, Number of adult females after $30 \mathrm{yr}$ in hypothetical populations where males are non-infanticidal. $\mathbf{b}$, Number of females in infanticidal populations; note that infanticidal populations are smaller and more vulnerable to trophy hunting. c. Total number of males harvested over $30 \mathrm{yr}$ in infanticidal populations. d, Total number of 5-6-yr-old 'trophies' harvested in infanticidal populations. quantity and the quality of the long-term kill. We present a simple non-invasive technique for estimating lion age in populations lacking long-term records, and suggest that quotas would be unnecessary in any male-only trophy species where age determination could be reliably implemented.

Male lions reach sexual maturity at about $2.5 \mathrm{yr}$ of age and live to a maximum of about $15 \mathrm{yr}$ in nature ${ }^{6}$. The lion's mane reaches full size at about $4 \mathrm{yr}$ (ref. 7), and peak reproductive success is attained by about $8 \mathrm{yr}$ (ref. 8). African lions live in stable social groups ('prides') containing an average of six breeding females and a coalition of 2-3 adult males. The resident coalition sires all cubs born during their tenure ${ }^{9}$, but most coalitions only remain resident for about $2 \mathrm{yr}$ on average-long enough to rear a single cohort of young to independence ${ }^{10}$. Rather than wait for mothers with dependent offspring to rear their current brood, incoming males typically kill all cubs $\leq 9$ months of age and evict older subadults when they first take over a pride $e^{4,5}$. Trophy hunting is expected to increase the rate of male takeovers, as larger coalitions dominate smaller ones ${ }^{11}$ and the loss of even one male from a resident coalition renders it more vulnerable to being ousted ${ }^{12}$.

We developed a comprehensive simulation model that tracks the fate of each individual in a population ${ }^{13}$ (see Methods), and we present results based on 'populations' comprising a maximum of ten prides of $\leq 9$ females per pride. Outcomes of hunting should be most sensitive to factors that limit population size: the maximum number of prides in the population, maximum pride size, and the incidence of infanticide. We therefore ran simulations of populations containing a maximum of five prides with $\leq 10$ females and ten prides with $\leq 7$ females, and our conclusions were unchanged. The impact of infanticide is emphasized below (see Fig. 1). At each six-month time step, animals survive and breed according to probabilities observed in the long-term lion studies in the Serengeti National Park and in Ngorongoro Crater ${ }^{14,15}$. Demographic parameters depend on the age, sex and social status of individual lions. Probability of female recruitment depends on the number of adult females in the pride, whereas probability of male takeovers depends on the size and age of resident coalitions versus challenging nomadic coalitions. An emerging property of these interactions is a density-dependence that leads to a quasi-equilibrium where the total population size fluctuates slightly (with demographic stochasticity) around a well-defined average. Preliminary trials started the populations with an arbitrary set of individuals and an arbitrary age
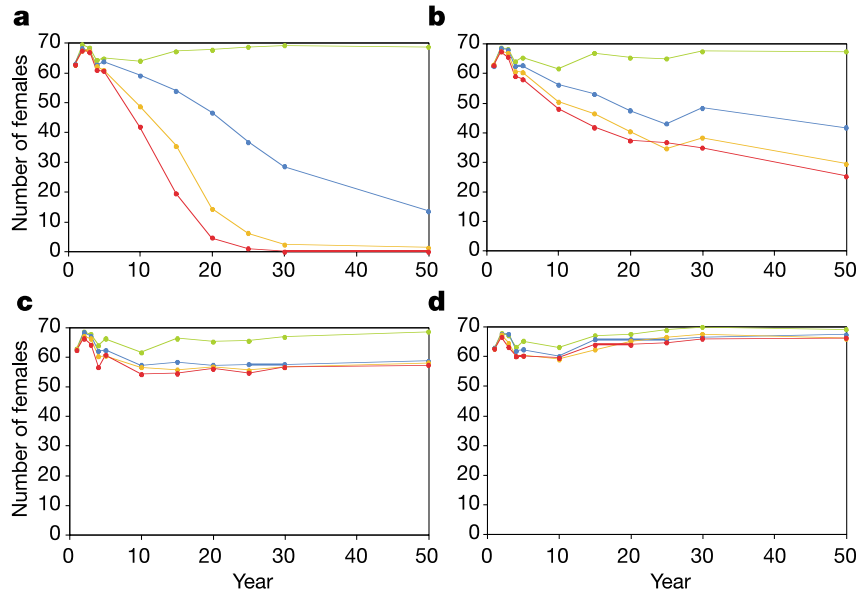

Figure 2 Female population size through time as a function of quota size and male age in infanticidal populations. Red indicates average outcome over 100 runs from an annual quota of 10 males, orange from a quota of 6 males, blue from a quota of 4 , and green from a quota of 2. a-dd, Female population size when hunters shoot males that are $\geq 3 \mathrm{yr}$ old $(\mathbf{a}), \geq 4 \mathrm{yr}(\mathbf{b}), \geq 5 \mathrm{yr}(\mathbf{c})$ and $\geq 6 \mathrm{yr}(\mathbf{d})$. 